\title{
Schistosomiasis mansoni of the prostate
}

Esquistossomose mansônica da próstata

\author{
José Roberto Lambertucci ${ }^{1}$, Izabela Voieta ${ }^{1}$ \\ and Alfredo José Afonso Barbosa²
}

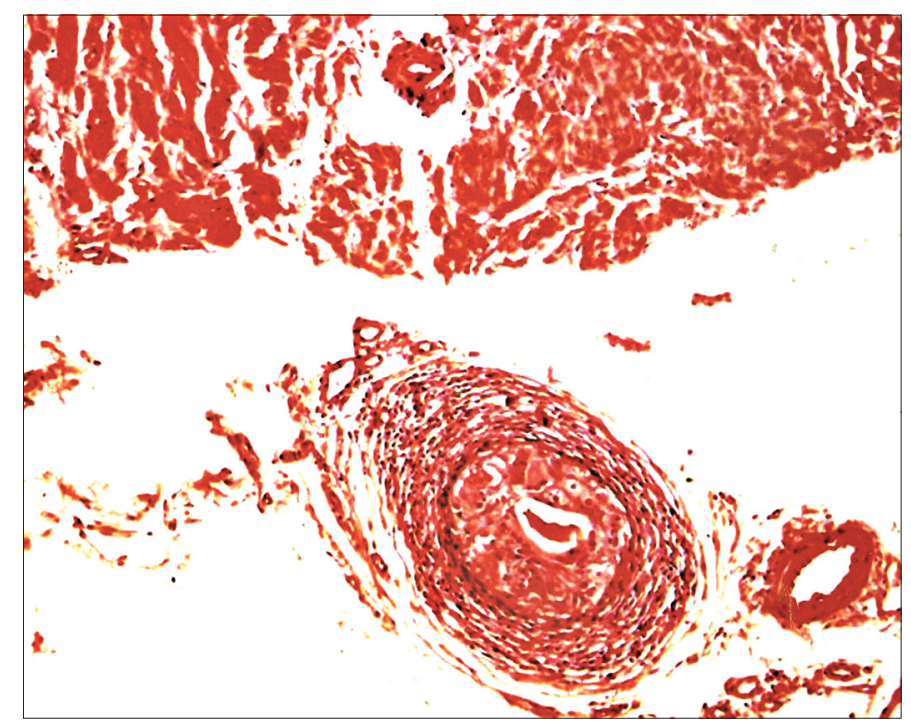

A

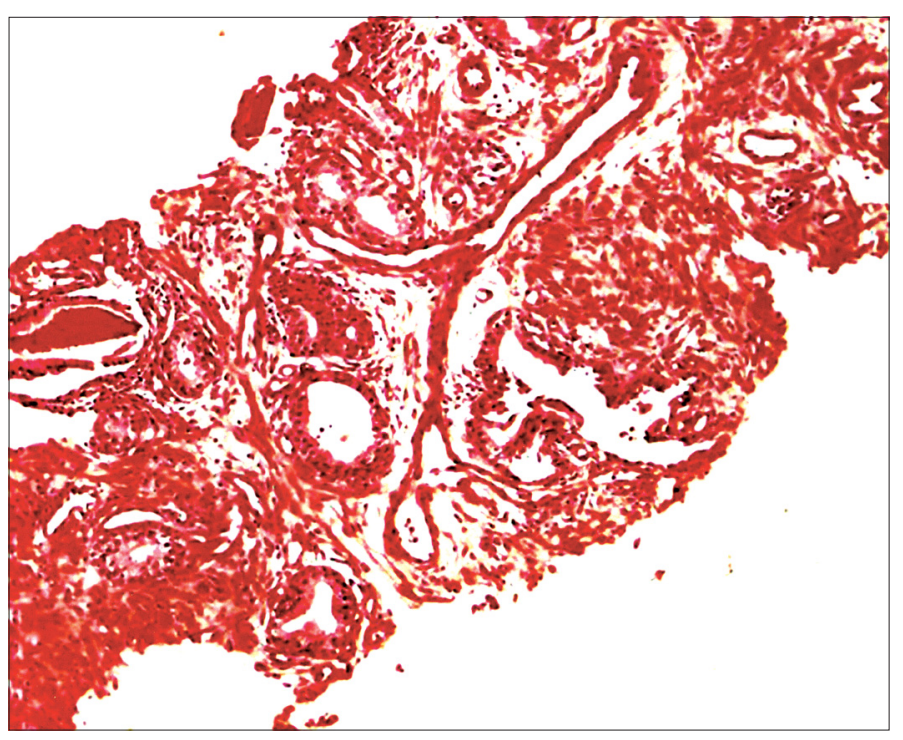

B

1. Serviço de Doenças Infecciosas e Parasitárias da Faculdade de Medicina da Universidade Federal de Minas Gerais, Belo Horizonte, MG, Brasil. 2. Serviço de Anatomia Patológica da Faculdade de Medicina da Universidade Federal de Minas Gerais, Belo Horizonte, MG, Brasil.

Address to: Dr. José Roberto Lambertucci. Deptº de Clínica Médica/FM/UFMG. Av. Alfredo Balena 190, 30130-100 Belo Horizonte, MG, Brasil.

e-mail: lamber@uai.com.br

Recebido para publicação em 9/11/2005

Aceito em 22/11/2005 
A 56-year-old man came to hospital for a routine check up. His medical history and physical examination were unremarkable. Laboratory evaluation was normal, except for a serum prostate specific antigen (PSA) of $6.5 \mathrm{ng} / \mathrm{mL}$ (reference values: $0-3.5 \mathrm{ng} / \mathrm{mL}$ ). Digital rectal examination revealed an enlarged well-delimitated prostate. Transrectal ultrasonography was normal. A biopsy retrieved 9 fragments of prostate tissue and histology showed no alterations. He was followed at the outpatient clinic for another 3 months and a second PSA showed increasing levels $(7.2 \mathrm{ng} / \mathrm{mL})$. A second transrectal biopsy showed no malignant infiltration of the prostate, but eggs of $S$. mansoni surrounded by characteristic granulomata were described (Figure A shows a granuloma surrounding an egg shell with a remnant miracidium and Figure B shows normal prostate tissue). The patient was treated with praziquantel $(60 \mathrm{mg} / \mathrm{kg}$, body weight, divided in two equal doses given at 4 hour intervals) and is being followed at the outpatient clinic. A diagnosis of adenocarcinoma of the prostate has not been discarded.

0 paciente, de 56 anos, veio ao hospital para exame de rotina. A sua história médica e o exame físico não revelaram alterações de importância. Os exames de laboratório mostraram-se normais, exceto pela elevação do nível do antígeno prostático específico no soro $(\mathrm{PSA}=6,5 \mathrm{ng} / \mathrm{mL}-$ valores de referência $=0-3,5 \mathrm{ng} / \mathrm{mL})$.
O toque retal revelou aumento da próstata e contornos bem delimitados. A ultra-sonografia transretal mostrou uma próstata de aspecto normal. Não houve alterações histológicas em nove fragmentos de tecido prostático obtido por biópsia. 0 paciente foi acompanhado em ambulatório por três meses e o segundo PSA aumentou para 7,2ng/mL. A segunda biópsia da próstata não revelou sinais de malignidade, mas evidenciou ovos de $S$. mansoni dentro de granulomas bem formados (Figura A: granuloma ao redor de casca de ovo contendo restos de um miracidio; Figura B: tecido prostático normal). 0 paciente foi tratado com praziquantel na dose de $60 \mathrm{mg} / \mathrm{kg}$ de peso, dividido em duas tomadas com intervalo de quatro horas. Ele continua sendo acompanhado em ambulatório. 0 diagnóstico de adenocarcinoma da próstata não foi descartado.

\section{REFERENCES}

1. Alexis R, Domingo J. Schistosomiasis and adenocarcinoma of the prostate: a morphologic study. Human Pathology 17: 757-760, 1986.

2. Andrade $\mathrm{Z}$, Bina JC. A patologia da forma hepatoesplênica da esquistossomose mansônica avançada. Memórias do Instituto Oswaldo Cruz 78: 285-305, 1983.

3. Oliveira CAB, Aquino A, Simon EF, Eyer-Silva WA. Concomitant prostate schistosomiasis and adenocarcinoma: case report and review. Brazilian Journal of Infectious Diseases 6: 45-49, 2002. 